Artículo de Investigación USO314006252. * Proyecto: "Indicadores de sustentabilidad en la industria minera”. Universidad de Sonora. * Recibido: 23.07.2019.

* Aprobado versión final: 27.12.2019. * JEL: Q3, Q32, Q5, Q56. * Pp.175-200. doi:10.33571/teuken.v11n16a8

\title{
La industria minera y su enfoque de sostenibilidad en Méjico.
}

\section{The mining industry and its sustainability approach in Mexico.}

\author{
María Eugenia De la Rosa Leal - Patricia Hernández García \\ Miguel Ángel Vega Campos \\ MÉJICO
}

Resumen: La minería en Méjico es esencial en la integración de la riqueza nacional y relevante en la política económica nacional. La riqueza de minerales como cobre, oro, plata, zinc, entre otros, es extensa. Esta industria tiene más de 300 años en funcionamiento y ha sido detonante de transformaciones económicas en varias regiones y en la generación de empleos y beneficios económicos que impactan el PIB nacional y regional. Lo anterior justifica la importancia de estudiar su posición ante la sostenibilidad por el efecto significativo en los ecosistemas y la comunidad aledaña a las vetas de explotación. Este artículo toma como muestra un grupo minero de Sonora y San Luis Potosí y aplica un estudio cualitativo de las prácticas de sostenibilidad.

Palabras clave: industria minera; indicadores de sostenibilidad; méjico.

\begin{abstract}
The mining in Mexico is momentous in the integration of national wealth and therefore relevant in the National Economic Policy. The richness of minerals such as copper, gold, silver, zinc, among others, is extensive. This industry has more than 300 years in operation and has been triggering economic transformations in several regions, creating a significant spillofofing of jobs and economic benefits that impact national and regional GDP. This underscores the importance of studying its position in the face of sustainability, in addition to the significant effect on ecosystems and the community surrounding the exploitation veins. This paper takes as a prototype a mining group in Sonora and San Luis Potosí, applying a qualitative study of sustainability practices.
\end{abstract}

Keywords: mining industry; sustainability indicators; mexico.

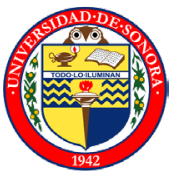

María Eugenia De la Rosa es Contadora Pública, Maestra en Administración y Doctora en Administración. Profesora investigadora de la Academia de Contabilidad Superior e integrante del Grupo de Investigación Contabilidad, Gestión y Fiscalización de la Universidad de Sonora.

Contacto: maedelarosa@hotmail.com - ORCID: https://orcid.org/0000-0003-2039-7263

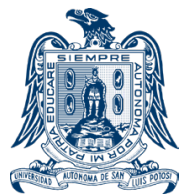

Patricia Hernández es Contadora Pública, Maestra en Administración y Doctora en Administración. Profesora Investigadora e integrante del Grupo de Investigación Nuevas Tendencias de Información Financiera para la Gestión de la Universidad Autónoma de San Luis Potosí.

Contacto: phernand_9918@yahoo.com.mx -ORCID: https://orcid.org/0000-0002-6214-8268 


\section{A indústria mineira e sua abordagem de sustentabilidade no México.}

Resumo: A mineração no México é importante na integração da riqueza nacional e, portanto, relevante na política econômica nacional. A riqueza de minerais como cobre, ouro, prata, zinco, entre outros, é extensa. Esta indústria tem mais de 300 anos de atuação e vem desencadeando transformações econômicas em diversas regiões, criando um grande derramamento de empregos e benefícios econômicos que impactam o PIB nacional e regional. Isso ressalta a importância de se estudar sua posição diante da sustentabilidade, além do efeito significativo sobre os ecossistemas e a Comunidade em torno das veias de exploração. Este trabalho assume como um protótipo um grupo mineiro em sonora e San Luis Potosí, aplicando um estudo qualitativo de práticas de sustentabilidade.

Palavras-chave: indústria mineira; indicadores de sustentabilidade; méxico.

\section{Introducción}

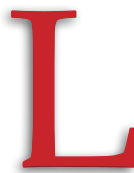

a sostenibilidad, desde una propuesta desarrollista, responde a una apertura a la racionalidad operativa del plan de negocios, con una lógica que establece metas sociales de beneficio a la comunidad y al entorno geográfico perimetral de la entidad. Desde los años 70, el medio ambiente y el compromiso social de las organizaciones económicas se han institucionalizado a través de distintas acciones, como las normas, convenios, tratados comerciales, reconocimientos como certificaciones 0 distintivos. Integrando opciones y recomendaciones ambientales y sociales como requisitos de competitividad internacional.

Para el caso de Méjico, el abordaje del tema de la industria minera es importante ya que "la actividad minera ha sido un factor fundamental de desarrollo en los 200 años de vida independiente de Méjico, de tal suerte que el país se forjó, en muchos aspectos, como resultado de la minería" (Gaytan y Benita, 2014:105). No obstante, a pesar de que la industria minera ha perdido protagonismo en el país, todavía cumple un rol significativo, como una de las principales opciones de trabajo y sustento de buena parte de la población en las zonas de explotación, territorios cuyas condiciones físico-geográficas extremas como obstaculizan el desarrollo de otras actividades económicas (Sánchez-Salazar, 2010).

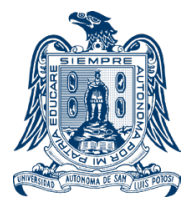

Miguel Ángel Vega es Licenciado en Administración Pública, Maestro en Administración y Doctor en Administración. Profesor Investigador y Coordinador de la Maestría en Dirección Empresarial de la Universidad Autónoma de San Luis Potosí. Líder del Cuerpo Académico (Consolidado) Innovación y Gestión en las Organizaciones (CA-212-UASLP) y miembro de la Red Administración y Gestión de las Organizaciones (RAGO).

Contacto: vegacamposnet@hotmail.com - ORCID: https://orcid.org/0000-0001-5576-863X 
Teniendo en cuenta el impacto interno y externo de los yacimientos de explotación, este trabajo estudia la gestión social de la industria minera, sus interpretaciones de responsabilidad, compromiso social y medioambiental, para determinar su visión y alcance, implicando la cadena de valor como efecto causal. La pregunta de investigación de este trabajo es ¿cuál es la interiorización de la sostenibilidad en la industria extractiva minera y su cadena de valor? Y el objetivo es comprender e interpretar la posición y el compromiso de la industria minera y su cadena de valor con la sostenibilidad en una gestión responsable, con disminución de riesgos ambientales asociados y posibles afectados.

El estudio se aplicó en unidades económicas mineras prototipo, que operan en dos zonas mineras de Méjico, San Luis Potosí y Sonora. La investigación fue de corte cualitativo para estudiar, desde el método semántico, el marco de gestión ambiental y social presentado en los informes anuales de desarrollo sostenible del Grupo México S.A.B de C.V. de 2006 a 2014. En el artículo se discute la pertinencia de considerar como social los alcances medioambientales, tomando como posición del discurso la separación de ambos, uniéndolos en razón de los argumentos y similitudes temporales de atención. A través del trabajo se detectan los niveles de gobierno en la cadena de valor y las estrategias que se utilizan como enfoque de desarrollo sustentable.

El artículo inicia con una descripción de la minería en el país y su importancia, continúa con la descripción regional en Sonora y San Luis Potosí como casos prototipo, analiza las implicaciones de la sostenibilidad y concluye con la descripción de los indicadores de sostenibilidad para la minería.

\section{Antecedentes}

El concepto de desarrollo sostenible ha sido rodeado por una serie de declaraciones, discursos y leyes que moldean su significado; no obstante, su punto de convergencia es el reconocimiento de que una organización económica no opera aislada de su contexto y goza de una licencia social que debe corresponder con beneficios sociales, desarrollo comunitario, estímulos a la educación y la cultura. A la par de un comportamiento ético, respetuoso, legal y transparente del uso de sus recursos y gestión responsable (Correa, 2004).

A pesar de las bondades económicas que la industria minera representa para las regiones, trae consigo una serie de inconvenientes que afectan directa o indirectamente el entorno en el que se desarrolla. Los efectos se pueden percibir en los campos ambiental, social y de salud, y con el 
paso del tiempo se perciben más agresivos, no solo con la población que habita los lugares en los que la industria minera se ha instalado, sino que también afecta las condiciones del entorno físico en el que se ubica (Delgado-Ramos, 2010).

La contaminación tóxica es uno de los problemas más frecuentes de este tipo de industria y se presenta por la utilización de sustancias químicas en alto grado que se requieren para extraer los minerales, las cuales, en la mayoría de los casos, no se han transportado y utilizado de acuerdo con las medidas sanitarias requeridas (Alfie-Cohen, 2015). Por otro lado, la industria minera requiere grandes cantidades de agua para la explotación de recursos, lo que también genera daños en las zonas en las que se encuentra instalada (Alfie-Cohen, 2015).

Frente a la problemática ambiental y social de la industria minera en Méjico, la política ambiental federal se ha dirigido como "un proceso integrador de decisiones, acciones, inacciones, acuerdos e instrumentos, con la participación eventual de los particulares, para solucionar o prevenir una situación definida como problemática" (Velásquez, 2009:156). Esta política expresa la visión de responsabilidad socio ambiental, regulada por la Ley General de Equilibrio Ecológico y Protección al Ambiente (LGEEPA) de 1988 y modificada en 1996, que legisla la protección de áreas naturales, clasificación de las fuentes de contaminación, uso de suelos, composición de los contaminantes en emisiones a la atmósfera, descargas de y al agua, control de residuos sólidos y residuos peligrosos, y sanciones por violación a la ley (Secretaria de Medio Ambiente y Recursos Naturales, 2001).

Sin embargo, da la impresión de que la LGEEPA propicia o protege las actividades peligrosas derivadas de la industria minera en Méjico, aun cuando las autoridades en la materia han promovido algunas acciones ambientales, como por ejemplo el Convenio de Concertación en Materia Ecológica para la Industria Minera Nacional celebrado en 1992, entre la Secretaría de Energía, Minas e Industria Paraestatal, la Cámara Minera de Méjico y la Secretaría de Desarrollo Social (Carmona-García, CardonaTrujillo y Retrepo-Tarquino, 2017).

El Convenio de Concertación permitió que se realizaran inversiones desde 1992, una suma de casi 40 millones de pesos en ese momento, por empresas mineras en Méjico en materia ambiental. También se fomentó el desarrollo del sistema de Normas Oficiales Mejicanas (NOM), que permitió lograr objetivos ambientales para buscar que la industria 
minera se convirtiera en una actividad "sostenible y amigable" con el ambiente y la salud comunitaria, considerando que con esto el sector minero se irá adaptando progresivamente a los principios básicos del desarrollo sostenible.

No obstante, para las autoridades mejicanas la industria minera representa un rubro importante para el desarrollo del país, por lo cual la legislación ambiental no es tan restrictiva en cuanto a sus impactos como debería ser, independientemente del método extractivo que utilice (Silva, 2010). En este sentido, todavía hace falta mayor exigencia en el cumplimiento de causas sociales por parte de la normatividad ambiental, lo cual pareciera que ha pasado a segundo término y la legislación se entiende como un trámite de procedimiento (Silva, 2010).

La industria minera en Méjico ha sido de gran importancia en distintas regiones del país, principalmente, en los estados del norte por la significativa generación económica de beneficios y empleos. Esta industria tiene más de 300 años en funcionamiento y ha generado transformaciones económicas, entre ellas el desarrollo de vías de comunicación como carreteras, ferrocarriles, puertos marítimos e incluso fundado poblaciones y revistiendo de auge al país en distintos momentos de la historia (Gracida, 2009).

Internacionalmente, Méjico se reconoce por la exportación de minerales preciosos como el oro, plata y cobre (Secretaria de Economía, 2014). Esta riqueza natural ha dado al país una imagen minera con tradición y arraigo nacional, cuyo sustento es la infraestructura geológica y minera de sus distintas regiones. Como parte de la extracción y producción minera se realiza la explotación y beneficio de minerales, purificación de metálicos crudos, separación de metales y la exportación de minerales metálicos y no metálicos, actividades que son importante reflexionar sobre sus consecuencias en los recursos naturales y la estructura de los sistemas ecológicos.

La poca regulación sobre los procesos de extracción que utiliza la industria minera, y considerando las altas utilidades que las empresas mineras pueden obtener en comparación con las bajas cargas fiscales o pagos de derechos, ha provocado que un alto número de empresas extranjeras se interesen por invertir en el país. "Aunado a los programas de promoción que realiza el gobierno, tan sólo en el año 2011 la lista de las 10 principales mineras con mayor número de proyectos no incluyó a ninguna empresa nacional" (Azamar y Ponce, 2014:155). 
El comportamiento de la industria minera y la adopción de criterios de sostenibilidad, desempeño ambiental, condiciones laborales, protección a la biodiversidad e interacción con la comunidad, en las cadenas de valor es resultado de la interacción entre empresas y partes interesadas, en particular del gobierno. La cadena de valor hace referencia a las actividades llevadas a cabo en diversas fases del proceso de fabricación para elaborar productos o servicios, desde la extracción hasta la entrega al consumidor final, elevando el valor de la cadena y otorgando a cada participante un papel dominante en la producción, comercialización, distribución o reciclaje (Kaplinsky \& Morris, 2001), como se representa en la figura 1.

Figura 1. Cadena de valor

\begin{tabular}{|c|c|c|c|c|c|}
\hline \multirow{4}{*}{$\begin{array}{l}\text { Actividades } \\
\text { de soporte }\end{array}$} & \multicolumn{5}{|c|}{ INFRAESTRUCTURAS Y SISTEMA } \\
\hline & \multicolumn{5}{|c|}{ RECURSOS HUMANOS } \\
\hline & \multicolumn{5}{|c|}{ TECNOLOGIA } \\
\hline & \multicolumn{5}{|c|}{ COMPRAS } \\
\hline $\begin{array}{l}\text { Actividades } \\
\text { primarias }\end{array}$ & $\begin{array}{l}\text { LOGISTICA DE } \\
\text { SALIDA }\end{array}$ & OPERACIONES & $\begin{array}{l}\text { LOGISTICA DE } \\
\text { ENTRADA }\end{array}$ & $\begin{array}{l}\text { MERCADEOY } \\
\text { VENTAS }\end{array}$ & $\begin{array}{l}\text { SERVICIOS DE } \\
\text { POST-VENTA }\end{array}$ \\
\hline
\end{tabular}

Fuente: Michael Porter (1986) citado por Quintero y Sánchez (2006:382).

Como se observa en el gráfico, la teoría de Michael Porter (1986) sobre las actividades de valor proyectadas en la cadena para crear una ventaja competitiva, se constituye con tres elementos: actividades primarias o básicas, actividades de soporte y el margen de diferencia. Las actividades primarias son los insumos, la comercialización y la logística; las de soporte implican la administración de recursos humanos, compra de bienes, desarrollo tecnológico, infraestructura y otras acciones para realización de las básicas y el margen de diferencia está determinado por el valor total y los costos totales acumulados (Quintero \& Sánchez, 2006) por cada valor agregado al producto, en donde todas las actividades estén relacionadas sistémicamente. Esta cadena como ventaja competitiva amplía el espectro del efecto de impacto en la sostenibilidad de la industria minera, agregando la filosofía de beneficio general del ciclo de consumo del líder y su cadena.

\section{Descripción general de la minería en Méjico}

Méjico se ha distinguido en el ámbito internacional por la exportación de minerales preciosos como el oro, plata y cobre, sin llegar a ser líder, pero se encuentra entre los primeros doce lugares. Según el Instituto Nacional 
de Estadística y Geografía (INEGI, 2014), Méjico ocupa el noveno lugar como productor de oro (tabla 1), el segundo puesto como productor de plata (tabla 2) y el lugar número doce como productor de cobre (tabla 3).

Tabla 1. Volumen de la producción de oro por país

\begin{tabular}{|l|c|c|c|c|c|c|}
\hline \multicolumn{7}{|c|}{ Serie anual de 2008 a $2013 \mathbf{~ K g . ) ~}$} \\
\hline País & $\mathbf{2 0 0 8}$ & $\mathbf{2 0 0 9}$ & $\mathbf{2 0 1 0}$ & $\mathbf{2 0 1 1}$ & $\mathbf{2 0 1 2}$ & $\mathbf{2 0 1 3}$ \\
\hline Total & 2.264 .818 & 2.352 .439 & 2.567 .376 & 2.664 .649 & 2.695 .705 & 2.789 .774 \\
\hline Australia & 215.000 & 220.000 & 261.000 & 258.000 & 250.000 & 255.000 \\
\hline Sudáfrica & 213.000 & 210.000 & 189.000 & 181.000 & 160.000 & 145.000 \\
\hline China, Rep. Popular & 285.000 & 300.000 & 345.000 & 362.000 & 403.000 & 420.000 \\
\hline Estados Unidos & 233.000 & 210.000 & 231.000 & 234.000 & 235.000 & 227.000 \\
\hline Perú & 180.000 & 180.000 & 164.000 & 164.000 & 161.000 & 150.000 \\
\hline Rusia & 176.000 & 185.000 & 192.000 & 200.000 & 218.000 & 220.000 \\
\hline Indonesia & 60.000 & 100.000 & 120.000 & 96.000 & 59.000 & 60.000 \\
\hline Canadá & 95.000 & 100.000 & 91.000 & 97.000 & 104.000 & 120.000 \\
\hline Méjico & $\mathbf{5 0 . 8 1 8}$ & $\mathbf{6 2 . 4 3 9}$ & $\mathbf{7 9 . 3 7 6}$ & $\mathbf{8 8 . 6 4 9}$ & $\mathbf{1 0 2 . 7 0 5}$ & $\mathbf{1 1 9 . 7 7 4}$ \\
\hline Otros países & 757.000 & 785.000 & 895.000 & 984.000 & 1.003 .000 & 1.073 .000 \\
\hline Nota: contenido metálico & & & & \\
\hline
\end{tabular}

Fuente: INEGI (2014).

Tabla 2. Volumen de la producción mundial de plata

\begin{tabular}{|l|c|c|c|c|c|c|}
\hline \multicolumn{7}{|c|}{ Serie anual de 2008 a 2013 (Ton.) } \\
\hline Total & $\mathbf{2 0 0 8}$ & $\mathbf{2 0 0 9}$ & $\mathbf{2 0 1 0}$ & $\mathbf{2 0 1 1}$ & $\mathbf{2 0 1 2}$ & $\mathbf{2 0 1 3}$ \\
\hline Perú & 21.296 & 22.404 & 23.101 & 23.930 & 25.498 & 26.421 \\
\hline Méjico & 3.690 & 3.900 & 3.640 & 3.410 & 3.480 & 3.500 \\
\hline China, Rep. Popular & 2.800 & 3.000 & 3.500 & 3.700 & 3.900 & 4.000 \\
\hline Australia & 1.930 & 1.800 & 1.860 & 1.730 & 1.730 & 1.700 \\
\hline Estados Unidos & 1.230 & 1.230 & 1.270 & 1.120 & 1.060 & 1.090 \\
\hline Canadá & 730 & 700 & 600 & 572 & 663 & 720 \\
\hline Otros países & 7.680 & 8.220 & 7.820 & 8.620 & 9.307 & 9.590 \\
\hline Nota: contenido metálico & $\mathbf{3 . 5 5 4}$ & $\mathbf{4 . 4 1 1}$ & $\mathbf{4 . 7 7 8}$ & $\mathbf{5 . 3 5 8}$ & $\mathbf{5 . 8 2 1}$ \\
\hline
\end{tabular}

Fuente: INEGI (2014). 
Tabla 3. Volumen de la producción mundial de cobre por países.

\begin{tabular}{|l|c|c|c|c|c|c|}
\hline \multicolumn{7}{|c|}{ Serie anual de $\mathbf{2 0 0 8}$ a $\mathbf{2 0 1 3}$ (miles de Ton.) } \\
\hline País & $\mathbf{2 0 0 8}$ & $\mathbf{2 0 0 9}$ & $\mathbf{2 0 1 0}$ & $\mathbf{2 0 1 1}$ & $\mathbf{2 0 1 2}$ & $\mathbf{2 0 1 3}$ \\
\hline Chile & 15.427 & 15.863 & 15.948 & 16.146 & 16.960 & 17.900 \\
\hline Perú & 5.330 & 5.390 & 5.420 & 5.260 & 5.430 & 5.700 \\
\hline Estados Unidos & 1.270 & 1.275 & 1.250 & 1.240 & 1.300 & 1.300 \\
\hline China, Rep. Popular & 1.310 & 1.180 & 1.110 & 1.110 & 1.170 & 1.220 \\
\hline Australia & 950 & 995 & 1.190 & 1.310 & 1.630 & 1.650 \\
\hline Indonesia & 886 & 854 & 870 & 958 & 958 & 990 \\
\hline Rusia & 651 & 996 & 872 & 543 & 360 & 380 \\
\hline Canadá & 750 & 725 & 703 & 713 & 883 & 930 \\
\hline Zambia & 607 & 491 & 525 & 566 & 579 & 630 \\
\hline Polonia & 546 & 697 & 690 & 668 & 690 & 830 \\
\hline Kazajstán & 430 & 439 & 425 & 427 & 427 & 430 \\
\hline Méjico & 420 & 390 & 380 & 417 & 424 & 440 \\
\hline Otros países & $\mathbf{2 4 7}$ & $\mathbf{2 4 1}$ & $\mathbf{2 7 0}$ & $\mathbf{4 4 4}$ & $\mathbf{5 0 0}$ & $\mathbf{4 8 0}$ \\
\hline Nota: contenido metálico & 2.030 & 2.190 & 2.243 & 2.490 & 2.609 & 2.920 \\
\hline
\end{tabular}

Fuente: INEGI (2014).

La producción de otros minerales se presenta a continuación:

Tabla 4. Estructura productiva minera nacional

\begin{tabular}{|c|c|c|c|c|c|c|c|}
\hline \multicolumn{8}{|c|}{ Producción minera metalúrgica 2013} \\
\hline $\begin{array}{l}\text { Metales } \\
\text { preciosos }\end{array}$ & $\begin{array}{l}\text { Total } \\
\text { producción } \\
\text { kgs. }\end{array}$ & $\begin{array}{c}\text { Metales } \\
\text { industriales } \\
\text { no ferrosos }\end{array}$ & $\begin{array}{l}\text { Total } \\
\text { producción } \\
\text { kgs. }\end{array}$ & $\begin{array}{c}\text { Metales y } \\
\text { minerales } \\
\text { siderúrgicos }\end{array}$ & $\begin{array}{l}\text { Total } \\
\text { producción } \\
\text { kgs. }\end{array}$ & $\begin{array}{c}\text { Minerales } \\
\text { no } \\
\text { metálicos }\end{array}$ & $\begin{array}{l}\text { Total } \\
\text { producción } \\
\text { kgs. }\end{array}$ \\
\hline Oro & 119.714 & Plomo & 253.361 & $\begin{array}{l}\text { Carbón no } \\
\text { coquizable }\end{array}$ & 13.065 .353 & Yeso & 5.090 .863 \\
\hline \multirow[t]{6}{*}{ Plata } & 5.820 .991 & Cobre & 480.124 & Coque & 2.216 .314 & Azufre & 1.025 .841 \\
\hline & & Zinc & 642.542 & Fierro & 8.093 .547 & $\begin{array}{l}\text { Arena } \\
\text { sílica }\end{array}$ & 2.937 .949 \\
\hline & & & & $\begin{array}{l}\text { Manga- } \\
\text { neso }\end{array}$ & 211.559 & Sal & 9.461 .320 \\
\hline & & & & & & Dolomita & 8.756 .485 \\
\hline & & & & & & Fluorita & 1.210 .477 \\
\hline & & & & & & Barita & 119.402 \\
\hline
\end{tabular}

Fuente: Elaboración propia con base en INEGI (2014). 
La mayor parte de los estados de Méjico tienen extracción minera, los de mayor producción son Zacatecas, en el centro del país, con plata, plomo, cobre y zinc, y Sonora, ubicado en el noroeste del país, con oro, plata y cobre. La explotación minera nacional se lleva a cabo por grupos corporativos, los más importantes son el Grupo Autlán, el Grupo México, Industrias Peñoles y Grupo San Luis. El Grupo Autlán opera en Nuevo León, Hidalgo, Puebla, Veracruz, Durango, Tamaulipas, Estado de Méjico y Distrito Federal. Por su parte, el Grupo México es un corporativo internacional que opera en Méjico, Chile, Perú, Estados Unidos y Argentina. En la República Mejicana se encuentra en Sonora, San Luis Potosí, Sinaloa, Guerrero, Coahuila, Baja California Sur, Chihuahua y Michoacán. Industrias Peñoles opera en Durango, Zacatecas, Chihuahua y Sonora, y el Grupo San Luis o Grupo SAN se encuentra en San Luis Potosí y Coahuila.

Como se observa en el mapa 1, de los 32 estados de la República 15 no tienen explotación minera. La industria extractiva minera representa el $70 \%$ de la inversión extranjera en el país y genera el $1 \%$ del PIB nacional, esto resalta su importancia económica por la oferta de empleo, la colonización de localidades y el impulso en la creación de infraestructura en distintas zonas.

Mapa 1. Unidades mineras en la República Mejicana

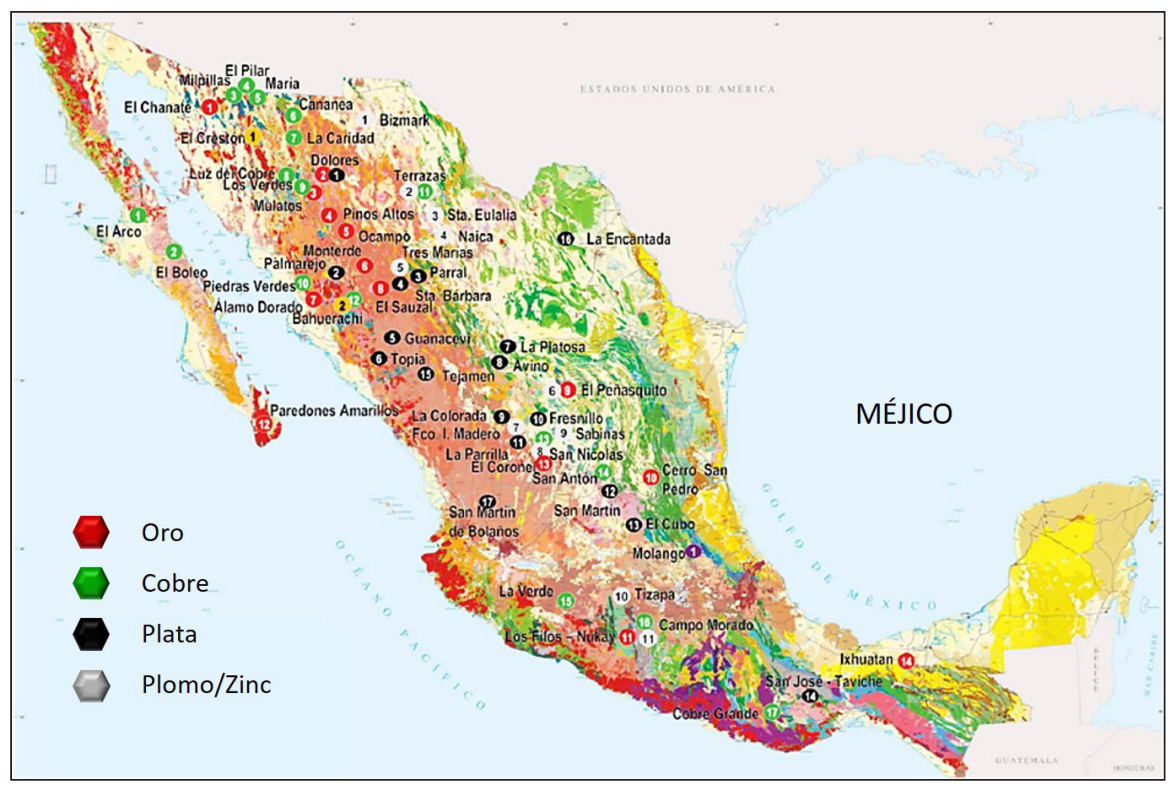

Fuente: SE-SGM (2014). 


\section{La minería en San Luis Potosí}

San Luis Potosí tiene una extensión territorial de 62,304.74 Km2., lo que representa el $3.22 \%$ del territorio nacional. Para 2014 tenía solo 12 concesiones mineras que representaban el $0.26 \%$ del total del Estado (SE-SGM, 2014). La minería es una actividad productiva muy importante y está integrada por 125 empresas que explotan minerales metálicos y no metálicos que generan 3,541 empleos directos aproximadamente (Sedeco, 2015). En 1561 se realizó el primer descubrimiento minero en San Luis Potosí en las Reales Salinas de Peñón Blanco, posteriormente en el municipio de Charcas y en el Cerro de San Pedro. En 1592 gracias a estas minas se fundó el pueblo de San Luis Minas del Potosí de la Nueva España. Actualmente, la minería en el Estado está enfocada a la exploración, explotación y beneficio de minerales (SE-SGM, 2014).

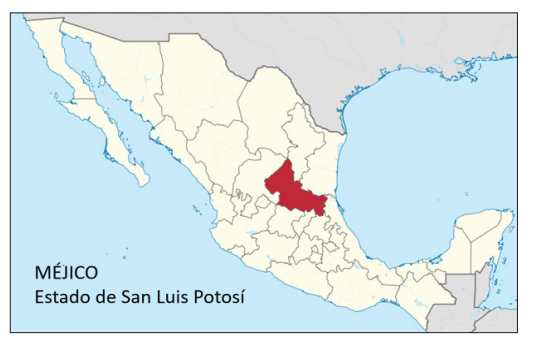

Entre 2006 y 2014 se presentó un auge en la minería derivado de la reactivación en esta zona de tales actividades por el alza de los precios de los metales, por parte de compañías mineras tanto nacionales como extranjeras (SE-SGM, 2014). Los principales distritos mineros de San Luis Potosí para productos metálicos son Cerro San Pedro, Charcas, Villa de la Paz y en menor escala Montaña de Manganeso y Wadley; mientras que en los productos no metálicos se destacan Las Cuevas, Cementos Moctezuma y Cementos Mexicanos (SE-SGM, 2014). De las principales empresas mineras de productos metálicos se destacan 5 , entre las cuales Industrial Minera México S.A. de CV se ubica en Charcas y en San Luis Potosí (SE-SGM, 2014).

\section{La minería en Sonora}

Sonora es un estado del noroeste de Méjico, caracterizado por una amplia industria extractiva minera, agrícola, ganadera y marina. Es el segundo estado más grande de Méjico, con 184,934 km2 que representan el 9.2\% del territorio nacional. La minería es motor de su desarrollo; actualmente existen cerca de 3.700 concesiones mineras, alrededor del $20 \%$ del total del territorio estatal. Sonora tiene en esta industria una de sus mayores riquezas de explotación de minerales metálicos y no metálicos, lo cual le da liderazgo nacional con importantes fuentes de empleo y desarrollo económico (Minería en Sonora, s.f.). 
Sonora ha sido considerado tradicionalmente un estado minero, de minerales metálicos como oro, plata, cobre y molibdeno; y no metálicos como grafito, wollastonita y barita, y ocupa desde hace tiempo el primer lugar nacional de explotación en sus minas de Buena Vista del

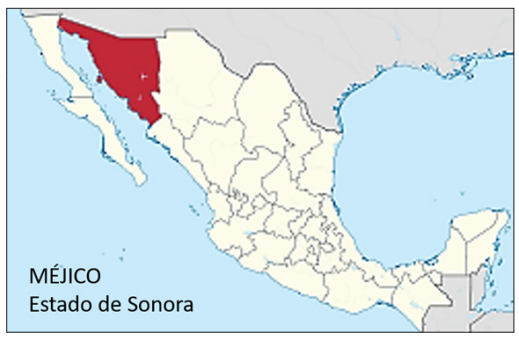
Cobre en Cananea y La Caridad en Nacozari de García. La industria minera en Sonora genera aproximadamente 14.000 empleos, con más de 5.000 concesiones mineras en un área de más de $43.000 \mathrm{~km}^{2}$ (Secretaría de Economía, 2014b).

El sector minero representa el $1.3 \%$ del PIB del Estado y el valor de la producción minera es de 2.8 billones (USD). Sonora ocupa el primer lugar a nivel nacional en el sector minero y el primero también a nivel nacional en diversidad geológica con las rocas más antiguas, así como en la producción de oro, cobre, grafito, wollastonita, molibdeno y carbón antracita (Secretaría de Economía, 2014a)

Se eligió como zona de estudio a Sonora por su participación en la actividad minera, ya que esta industria ha marcado el rumbo de la actividad económica estatal, ligando a la economía sonorense con el mercado mundial por su producción en modernos centros mineros con escalas de producción significativas (Gracida, 2009:12-13).

En Sonora la explotación minera tiene más de 305 años y ha sido a cielo abierto y en el subsuelo, actualmente, se realiza a cielo abierto. En los años 90 , se dio el auge en la exploración de yacimientos auríferos de baja ley y gran volumen, atrayendo empresas de capital estadounidense y canadiense, las cuales establecieron la explotación del mineral en La Colorada, Santa Gertrudis, Amelia, La Choya, Lluvia de Oro, El Boludo, San Francisco, La Herradura, Mulatos y El Chanate, algunos agotados ya. Posteriormente, se han explotado yacimientos de cobre y plata en Mariquita, Milpillas, Luz del Cobre, Piedras Verdes y Álamo Dorado (Secretaría de Economía, 2014b), ilustrados en el mapa 2.

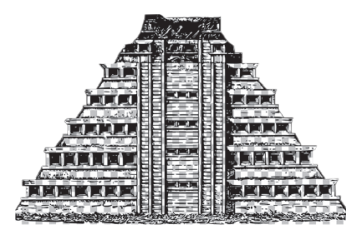


Mapa 2. Municipios con explotación minera en Sonora

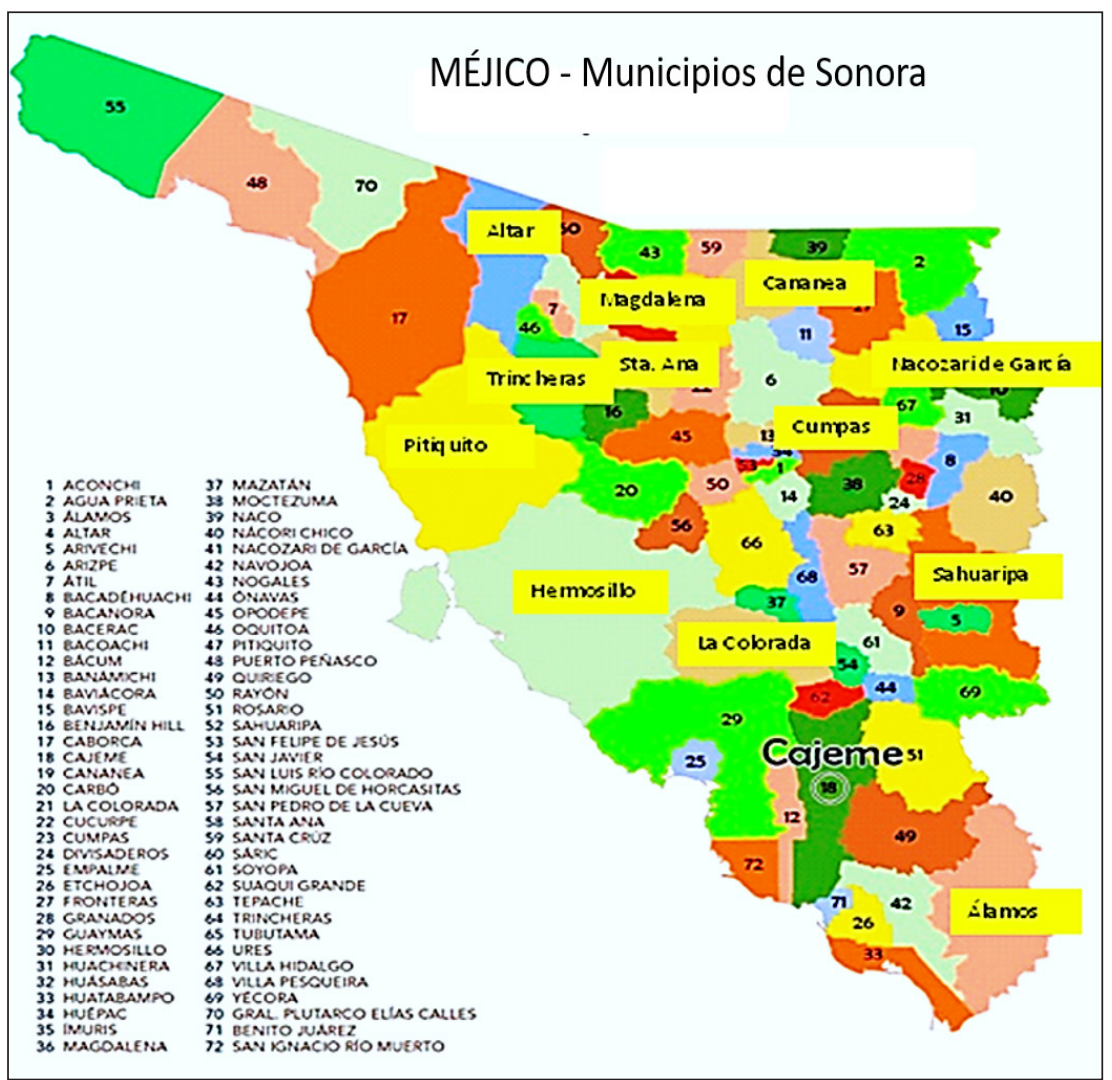

Fuente: Elaboración propia con base en Gracida (2009) y Municipios de Sonora (s.f.).

Los municipios que se han considerado los más importantes productores mineros en Sonora (Secretaría de Economía, 2013) son:

- Caborca, Sahuaripa, Santa Ana, Álamos, Altar y Trincheras producen el $90 \%$ de la producción de oro;

- Nacozari, Santa Cruz y Cananea tienen la producción total de cobre del Estado;

- Nacozari de García y Cumpas son los principales municipios productores de molibdeno;

- La Colorada representa el $100 \%$ de la producción de grafito amorfo;

- Hermosillo el $100 \%$ de la producción de wollastonita;

- Álamos desarrolla el $100 \%$ de la producción de yeso. 
Las empresas mineras que operan en Sonora son el Grupo México, Grupo Peñoles, Grupo FRISCO, Arcelor-Mittal, Minas de Oro Nacionales, Minera Rincón Bay, Molymex de Méjico, Canadá, Chile, Australia y Estados Unidos (Secretaría de Economía, 2014b). El capital actual de inversión en la industria minera sonorense tiene una mezcla nacional, canadiense y estadounidense.

Sonora tiene como principal actividad económica la extracción minera, con un volumen de explotación en crecimiento desde 2007, esto permite establecer su representatividad como estado prototipo en la explotación minera.

En Sonora se localizan las dos minas más importantes en producción de cobre de México y a nivel Latinoamérica, en los municipios de Cananea y Nacozari y las dos minas productoras de oro más importantes del país en los municipios de Pitiquito y Sahuaripa (...) Sonora produce además el $84 \%$ del cobre, el $28.6 \%$ del oro e importantes porcentajes de plata y otros minerales; el valor de la producción minera de Sonora constituye alrededor del $50 \%$ del total de la producción nacional, sobrepasando los 31 mil 500 millones de pesos. El volumen de la producción minera de Sonora es superior a un millón 780 mil toneladas de diversos productos (Minería en Sonora, s.f.).

\section{Las conductas de sostenibilidad}

El objetivo de la investigación es comprender las implicaciones de la industria minera desde el enfoque de la sostenibilidad, como un modelo teórico que evalúa la gestión interna disgregando sus principales actividades como eslabones generadores de valor, que forman un proceso compuesto por diseño, producción, promoción, venta, distribución del producto, las cuales van añadiendo valor al producto (Ampuero, 2012). Los elementos básicos de la cadena de valor (Porter citado por Quintero y Sánchez, 2006) son:

- Las actividades primarias formadas en el desarrollo del producto; y

- Las actividades soporte.

En la cadena de valor, las de mayor interés son desarrollo de tecnología, operaciones y logística externa, ya que tienen mayor posibilidad de generar valor. La cadena de valor de la industria extractiva minera se presenta en la tabla 5. 
Tabla 5. Cadena de valor en la industria extractiva minera

\begin{tabular}{|c|c|c|c|}
\hline \multicolumn{4}{|c|}{ Cadena de valor } \\
\hline $\begin{array}{l}\text { Actividades } \\
\text { primarias } \\
\text { o de línea }\end{array}$ & $\begin{array}{l}\text { Actividades directas } \\
\text { Actividades indirectas } \\
\text { Actividades de } \\
\text { control }\end{array}$ & $\begin{array}{l}\text { - Creación física } \\
\text { - del producto } \\
\text { - Diseño producto } \\
\text { - Fabricación } \\
\text { - Venta } \\
\text { - Servicio postventa }\end{array}$ & \multirow[b]{2}{*}{$\begin{array}{l}\text { - Logística interna } \\
\text { - Operaciones } \\
\text { - Logística externa } \\
\text { - Marketing y Ventas } \\
\text { - Servicios }\end{array}$} \\
\hline $\begin{array}{l}\text { Actividades } \\
\text { secundarias } \\
\text { o de apoyo }\end{array}$ & & $\begin{array}{l}\text { - Infraestructura } \\
\text { empresarial } \\
\text { - Administración de } \\
\text { recursos humanos } \\
\text { - Desarrollo de } \\
\text { tecnología } \\
\text { - Abastecimiento }\end{array}$ & \\
\hline \multicolumn{4}{|c|}{ Margen de intervención } \\
\hline \multicolumn{2}{|c|}{$\begin{array}{l}\text { Cadena de valor } \\
\text { de los proveedores }\end{array}$} & & $\begin{array}{l}\text { Cadena de valor } \\
\text { de los clientes }\end{array}$ \\
\hline
\end{tabular}

Fuente: Elaboración propia con base en Ampuero (2012).

El enfoque teórico de este trabajo se orientó hacia las conductas sostenibles, entendidas como el "conjunto de acciones efectivas y deliberadas que tienen como finalidad el cuidado de los recursos naturales y socioculturales necesarios para garantizar el bienestar presente y futuro de la humanidad" (Corral y Pinheiro, 2004 citado por Corral, 2010). Entre el deber, el hacer, las capacidades y posibilidades se introduce el concepto de conducta sostenible como una manera de distinguir los comportamientos y visiones que dirigen una acción.

El concepto de desarrollo sostenible en los productos que provienen de la tierra, como los de la minería, con recursos minerales limitados, su explotación tiene repercusiones en generaciones presentes y futuras, por su disponibilidad y el manejo de desechos. El concepto se vuelve complejo al hablar de equidad, modernización, empleo, mejora en la calidad de vida, estabilidad, relaciones con la comunidad, uso racional de los recursos, protección a la biodiversidad y, en general, el mejoramiento de las relaciones y condiciones naturales (Fuente y Barkin, 2013). La representación del efecto de la actividad minera se ilustra en la figura 2.

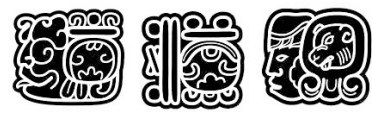


Figura 2. Efecto industria minera

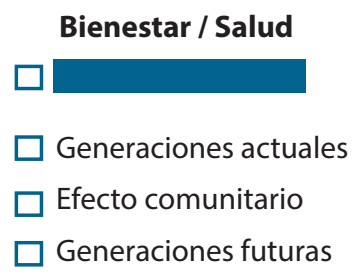

\author{
Capacidades / Posibilidades \\ $\square$ \\ Modernidad \\ Empleo \\ Mejora en la calidad de vida \\ Estabilidad económica \\ Explotación recursos limitados \\ Manejo de desechos \\ Protección a la biodiversidad
}

\section{$\square$ \\ Entre el deber y el hacer}

Fuente: Elaboración propia con base en Fuente y Barkin (2013).

El efecto entre deber y hacer de la industria extractiva minera genera un beneficio en las generaciones actuales, teniendo en contra tres actividades que atentan contra el futuro: la explotación de recursos limitados, el manejo de desechos y la protección de biodiversidad. Además, lo definen los aspectos ambientales, económicos y sociales, como una combinación para garantizar la vida digna de las generaciones futuras sin dañar la integridad del entorno natural.

Las operaciones mineras generalmente siguen una proceso similar, conocido como cadena de valor de la mina o Mine Value Chain (MVC):

Figura 3. Cadena de valor industria minera

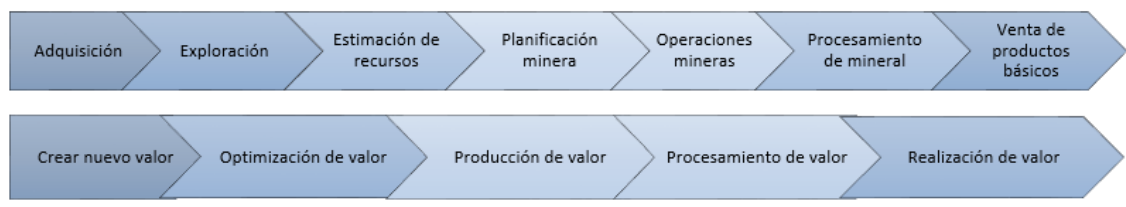

Fuente: Bester, Russel, Heerden \& Carey (2016:116).

La fila superior representa los procesos de alto nivel a lo largo de la cadena de valor y la fila inferior representa el valor. La realización del valor generado a lo largo de MVC depende directamente de la precisión, planificación y ejecución controlada de los diferentes procesos que apoyan la cadena de valor. 
De acuerdo con Díaz Porras y Valenciano Salazar (2012) la gobernabilidad en la industria minera se caracteriza por la integración vertical y el control administrativo ejercido por un grupo directivo, donde grandes empresas abarcan más de un segmento de la cadena de valor (figura 4).

Figura 4. Gobernanza y efecto de la cadena de valor de una entidad minera

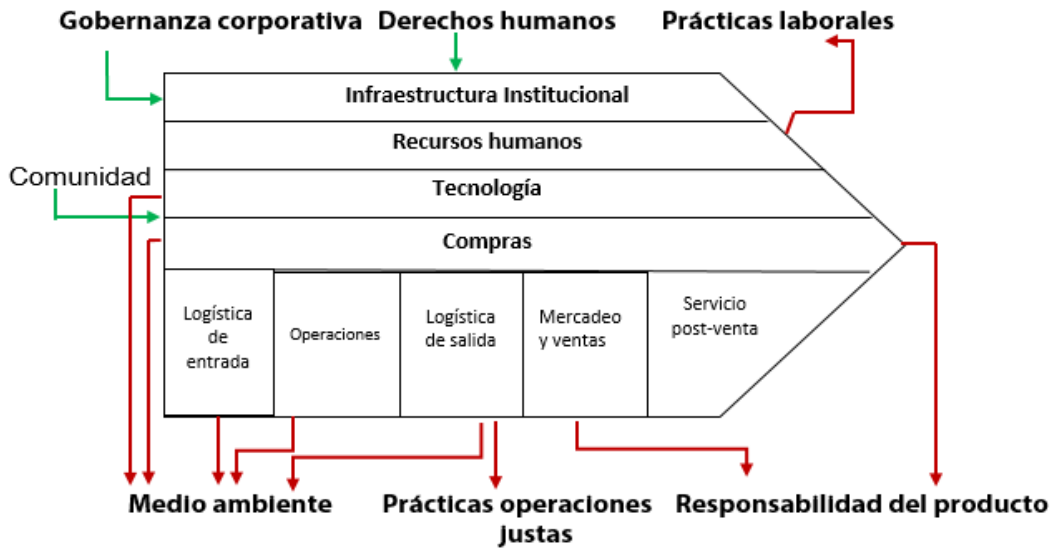

Fuente: Guajardo (2013).

El efecto de extracción minera es dirigido por la corporación y se dirige en dos sentidos: internamente hacia los derechos humanos y las prácticas laborales; y externamente hacia la comunidad en el medio ambiente y el ciclo del producto. Este impacto está dado por la gestión de los elementos de la cadena: recursos humanos, tecnología, compras, logística y mercadeo.

El daño ambiental sucede desde el inicio hasta la finalización de la operación minera (Mining Environmental Management, 2001b), por lo que es importante implementar medidas y prácticas ambientales que puedan reducir esos impactos. Éstos pueden ser de tres tipos: el impacto visual, el impacto social y el impacto ambiental, con la posibilidad de utilizar tecnologías asociadas para minimizar el riesgo, lo cual requiere una fuerte inversión económica (Bowell \& Pearce, 2000, Komnitsas et al., 2000, Davies, 2001, Kuyucak, 2001, Mining Environmental Management, 2001a). Existen otros retos tecnológicos para reducir otros impactos, por ejemplo: el manejo de desechos de mina, la infraestructura, deslaves, las aguas toxicas, entre otros. 


\section{Indicadores y conductas de sostenibilidad en la industria extractiva minera}

Con el objetivo de comprender e interpretar la posición con la sostenibilidad de la industria minera y su cadena en una gestión o gobernanza responsable, con disminución de riesgos ambientales y de posibles afectados, se tomó como prototipo el Grupo México S.A.B de C.V. que opera en los estados de Sonora y San Luís Potosí. Desde el método semántico (Sayago, 2014) se busca comprender el marco de gestión ambiental y social declarado en los informes anuales de desarrollo sostenible de 2006 a $2014^{1}$ del Grupo. Los supuestos de estudio fueron:

S1: Los indicadores sociales se relacionan con conductas sostenibles internas y externas.

S2: Los indicadores ambientales se relacionan con conductas sostenibles internas y externas.

Los indicadores encontrados fueron establecidos por el grupo administrador, con el enfoque de usuario general, cuidando su imagen mercadológica. Se estudiaron los datos de transparencia que permiten captar la posición de la empresa socio-ambiental en forma directa con su actividad extractiva, el análisis taxonómico arrojó las siguientes categorías:

- Indicadores de dirección y gestión.

- Indicadores de gestión económico-social.

- Indicadores de gestión ambiental.

- Indicadores de gestión social.

Los indicadores se establecieron por acciones concretas y declaraciones específicas de acciones realizadas e informadas. Los informes se suman como grupo corporativo de extracción minera en el país y presentan las zonas de la muestra de estudio. Los resultados del análisis de los informes de gestión social y sostenibilidad analizados se presentan en las tablas 6 y 7.

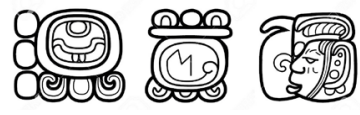

1 Último período que el Grupo México S.A.B de C.V. publica en su página web los informes al momento de realizarse la investigación (mayo 2019). 
Tabla 6. Indicadores de gestión socio-ambiental Grupo México (2006-2014)

Indicadores

$\begin{array}{lllllllll}2006 & 2007 & 2008 & 2009 & 2010 & 2011 & 2012 & 2013 & 2014\end{array}$

\section{Frecuencia Absoluta}

\begin{tabular}{|c|c|c|c|c|c|c|c|c|c|}
\hline \multicolumn{10}{|c|}{ Indicadores de Dirección y Gestión } \\
\hline Estrategia y análisis & 2 & 2 & 2 & 2 & 2 & 2 & 2 & 2 & 2 \\
\hline Perfil de la organización & 8 & 8 & 10 & 10 & 10 & 10 & 10 & 10 & 10 \\
\hline Parámetros de la memoria & 2 & 3 & 4 & 4 & 4 & 4 & 4 & 4 & 3 \\
\hline $\begin{array}{l}\text { Alcance y cobertura } \\
\text { de la memoria }\end{array}$ & 7 & 7 & 7 & 7 & 7 & 7 & 7 & 5 & 5 \\
\hline \multicolumn{10}{|l|}{ Índice del contenido del GRI } \\
\hline Verificación & 1 & 1 & 1 & 1 & 1 & 1 & 1 & 1 & 1 \\
\hline Gobierno de la organización & 8 & 7 & 5 & 10 & 9 & 10 & 10 & 10 & 10 \\
\hline $\begin{array}{l}\text { Compromisos con } \\
\text { iniciativas externas }\end{array}$ & 3 & 3 & 3 & 3 & 3 & 3 & 3 & 3 & 3 \\
\hline $\begin{array}{l}\text { Participación de los grupos } \\
\text { de interés }\end{array}$ & 4 & 4 & 4 & 4 & 3 & 4 & 4 & 4 & 4 \\
\hline \multicolumn{10}{|c|}{ Indicadores de Gestión Económico-Social } \\
\hline $\begin{array}{l}\text { Desempeño } \\
\text { económico-social }\end{array}$ & 4 & 4 & 2 & 4 & 4 & 4 & 3 & 3 & 3 \\
\hline Presencia en el mercado & 3 & 3 & 3 & 3 & 3 & 3 & 3 & 3 & 3 \\
\hline $\begin{array}{l}\text { Impactos económicos } \\
\text { indirectos }\end{array}$ & 4 & 6 & 4 & 2 & 2 & 2 & 2 & 1 & 1 \\
\hline \multicolumn{10}{|c|}{ Indicadores de Gestión Ambiental } \\
\hline $\begin{array}{l}\text { Explotación y uso de } \\
\text { materiales }\end{array}$ & 1 & 1 & 1 & 2 & 2 & 3 & 3 & 3 & 3 \\
\hline $\begin{array}{l}\text { Energía renovable y no } \\
\text { renovable }\end{array}$ & 5 & 4 & 4 & 5 & 5 & 5 & 4 & 4 & 4 \\
\hline Agua & 3 & 3 & 2 & 3 & 3 & 3 & 3 & 3 & 3 \\
\hline Biodiversidad & 6 & 6 & 5 & 6 & 6 & 7 & 5 & 5 & 6 \\
\hline $\begin{array}{l}\text { Emisiones, vertidos y resi- } \\
\text { duos }\end{array}$ & 12 & 8 & 7 & 11 & 10 & 9 & 11 & 10 & 7 \\
\hline Productos y servicios & 2 & 1 & 1 & 2 & 2 & 2 & 2 & 2 & 2 \\
\hline Cumplimiento normativo & 6 & 5 & 2 & 3 & 3 & 3 & 3 & 3 & 3 \\
\hline \multicolumn{10}{|c|}{ Indicadores de Gestión Social } \\
\hline Prácticas laborales & 17 & 9 & 5 & 15 & 15 & 7 & 12 & 12 & 13 \\
\hline Derechos humanos & 14 & 10 & 5 & 4 & 4 & 9 & 3 & 2 & 2 \\
\hline Social & 11 & 8 & 5 & 7 & 7 & 7 & 7 & 7 & 7 \\
\hline Gobierno & 9 & 6 & 4 & 6 & 6 & 6 & 6 & 6 & 6 \\
\hline Comunidades & 7 & 6 & 4 & 1 & 1 & 3 & 3 & 2 & 2 \\
\hline Competencia & 8 & 7 & 4 & 8 & 8 & 8 & 6 & 6 & 6 \\
\hline Total indicadores & 147 & 122 & 94 & 123 & 120 & 122 & 117 & 111 & 109 \\
\hline
\end{tabular}

Fuente: Elaboración propia basada en informes de sostenibilidad del Grupo México. 
Como se observa, el Grupo México establece sus indicadores como una forma se seguimiento de sus acciones, algunos de ellos siguen el modelo Global Reporting Iniciative (GRI) y otros las normas NOM, utilizando el manejo de ilustraciones ad hoc en sus informes. Se presentó un total de 25 tipos de indicadores de 2006 a 2014, con 147 a 109 acciones, de acuerdo con el resumen de la tabla 7.

Tabla 7. Indicadores de gestión socio-ambiental Grupo México 2006 - 2014

\begin{tabular}{|l|c|c|c|c|c|c|c|c|c|}
\hline \multicolumn{1}{|c|}{ Indicadores } & 2006 & 2007 & 2008 & 2009 & 2010 & 2011 & 2012 & 2013 & 2014 \\
\hline $\begin{array}{l}\text { Indicadores de } \\
\text { Dirección y Gestión (9) }\end{array}$ & 35 & 35 & 36 & 41 & 39 & 41 & 41 & 39 & 38 \\
\hline $\begin{array}{l}\text { Indicadores de } \\
\text { Gestión Económico- } \\
\text { Social (3) }\end{array}$ & 11 & 13 & 9 & 9 & 9 & 9 & 8 & 7 & 7 \\
\hline $\begin{array}{l}\text { Indicadores de Ges- } \\
\text { tión Ambiental (7) }\end{array}$ & 35 & 28 & 22 & 32 & 31 & 32 & 31 & 30 & 28 \\
\hline $\begin{array}{l}\text { Indicadores de } \\
\text { Gestión Social (6) }\end{array}$ & 66 & 46 & 27 & 41 & 41 & 40 & 37 & 35 & 36 \\
\hline Suma indicadores & 147 & 122 & 94 & 123 & 120 & 122 & 117 & 111 & 109 \\
\hline $\begin{array}{l}\text { Indicadores } \\
\text { de Desarrollo } \\
\text { Sostenible }\end{array}$ & 112 & 94 & 72 & 91 & 89 & 90 & 86 & 81 & 81 \\
\hline
\end{tabular}

Fuente: Elaboración propia con base en los informes de sostenibilidad del Grupo México.

Fueron tres los indicadores de mayor énfasis: Gestión social, Dirección y Gestión y Gestión ambiental, como se aprecia en el gráfico 1, el cual también muestra cómo las acciones van ajustándose de forma paralela a la gestión ambiental.

Gráfico 1. Tendencia de ajuste de indicadores Grupo México 2006-2014

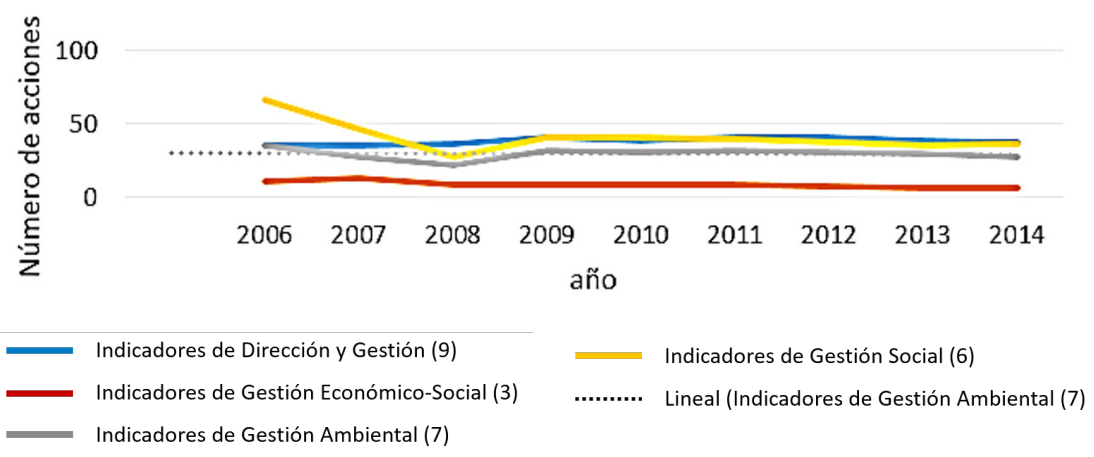

Fuente: Elaboración propia con base en los informes de sostenibilidad. 
La interpretación de los grupos de indicadores de desarrollo sostenible es:

Indicadores de Gestión Económica-Social

- Desempeño económico: inversiones sociales y cambio climático.

- Presencia en el mercado: equidad laboral, contratos laborales y proveedores.

- Impactos económicos indirectos: infraestructura social, donaciones.

Indicadores de Gestión Ambiental

- Materiales: recursos naturales.

- Energía renovable y no renovable: uso y reducción.

- Agua: uso, reciclaje y reutilización.

- Biodiversidad: descripción áreas de explotación, protegidas, reservas.

- Emisiones, vertidos y residuos totales, directos, indirectos; agua, aire y tierra.

- Productos y servicios: mitigación ciclo del producto o servicio.

- Cumplimiento normativo: inversiones ambientales, máximos autorizados, transporte y multas.

Indicadores de Gestión Social

- Prácticas laborales: contratos, planta laboral, género; prestaciones sociales, huelgas, discriminación, salud y seguridad, beneficio familiar.

- Derechos humanos: beneficios a empleados, jerarquía, tabulador, tipo de contratación, plazas, jubilación, edad y género.

- Social: políticas y acciones de apoyo o incidencias sobre derechos de asociación, trabajo forzado e infantil, pueblos indígenas.

- Gobierno: informes, controversias, actos de anticorrupción, sanciones.

- Comunidades: asentamientos, emergencias, extracción y cierre.

- Competencia: productos, clientes, competencia, mercadotecnia.

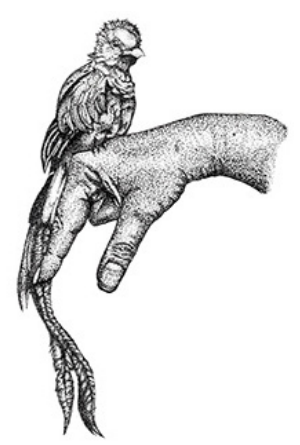


La información sigue un hilo conductor: demostrar el compromiso con la comunidad y los pueblos originarios, cumplir estrictamente con las normas legales de todo tipo, resaltar la importancia de la presencia de la mina en la región, por las donaciones y la gestión social paralela a su actividad sin involucrarla. Los informes hacen énfasis en la necesidad de evitar conflictos y buscar de forma expedita la solución de controversias; no revelando su posición de deterioro ambiental, sino dando un tratamiento emergente a los riesgos ambientales. Estos aspectos denotan una posición de fortaleza de la gobernanza hacia los intereses del grupo directivo y la protección del capital, incluyendo la cadena de valor en el corporativo.

Por otro lado, Ilama la atención la baja revelación del incidente ambiental en Sonora en 2014, cuya revelación se ajusta al modelo establecido de sus informes de sostenibilidad, siendo casi igual al del año anterior. Analizando al detalle las acciones y su interiorización en el concepto de sostenibilidad, la interpretación ponderada del Grupo México se presenta en la tabla 8.

Tabla 8. Carga ponderada de actividades significativas de sostenibilidad Grupo Méjico

\begin{tabular}{|c|c|c|c|c|c|c|c|c|c|}
\hline Indicadores & 2006 & 2007 & 2008 & 2009 & 2010 & 2011 & 2012 & 2013 & 2014 \\
\hline \multicolumn{10}{|c|}{ Valores ponderados (\%) } \\
\hline \multicolumn{10}{|c|}{ Indicadores de Dirección y Gestión } \\
\hline Perfil de la organización & 23 & 23 & 28 & 24 & 26 & 24 & 24 & 26 & 26 \\
\hline Gobierno de la organización & 23 & 20 & 14 & 24 & 23 & 24 & 24 & 26 & 26 \\
\hline $\begin{array}{l}\text { Carga ponderada } \\
\text { indicadores de Dirección } \\
\text { y Gestión }\end{array}$ & 46 & 43 & 42 & 48 & 49 & 48 & 48 & 52 & 52 \\
\hline \multicolumn{10}{|c|}{ Indicadores de Gestión Económico-Social } \\
\hline $\begin{array}{l}\text { Desempeño económico } \\
\text { (inversiones sociales } \\
\text { y cambio climático) }\end{array}$ & 36 & 31 & 22 & 44 & 44 & 44 & 38 & 43 & 43 \\
\hline $\begin{array}{l}\text { Impactos económicos } \\
\text { indirectos (infraestructura } \\
\text { social, donaciones) }\end{array}$ & 36 & 46 & 44 & 22 & 22 & 22 & 25 & 14 & 14 \\
\hline $\begin{array}{l}\text { Carga ponderada } \\
\text { indicadores de gestión } \\
\text { económica-social }\end{array}$ & 72 & 77 & 66 & 66 & 66 & 66 & 63 & 57 & 57 \\
\hline \multicolumn{10}{|c|}{ Indicadores de Gestión Ambiental } \\
\hline $\begin{array}{l}\text { Emisiones, vertidos } \\
\text { y residuos ( totales, } \\
\text { directos, indirectos) } \\
\text { ( agua, aire y tierra) }\end{array}$ & 34 & 29 & 32 & 34 & 32 & 28 & 35 & 33 & 25 \\
\hline $\begin{array}{l}\text { Carga ponderada } \\
\text { indicadores de gestión } \\
\text { ambiental }\end{array}$ & 34 & 29 & 32 & 34 & 32 & 28 & 35 & 33 & 25 \\
\hline
\end{tabular}




\begin{tabular}{|c|c|c|c|c|c|c|c|c|c|}
\hline \multicolumn{10}{|c|}{ Valores ponderados (\%) } \\
\hline \multicolumn{10}{|c|}{ Indicadores de Gestión Social } \\
\hline $\begin{array}{l}\text { Prácticas laborales (contrato, } \\
\text { planta laboral, género; } \\
\text { prestaciones sociales, } \\
\text { huelgas, discriminación, } \\
\text { salud y seguridad, beneficio } \\
\text { familiar) }\end{array}$ & 26 & 20 & 19 & 37 & 37 & 18 & 32 & 34 & 36 \\
\hline $\begin{array}{l}\text { Derechos humanos } \\
\text { (beneficios a empleados, } \\
\text { tabulador, tipo de } \\
\text { contratación, plazas, } \\
\text { jubilación, edad y género) }\end{array}$ & 21 & 22 & 19 & 10 & 10 & 23 & 8 & 6 & 6 \\
\hline $\begin{array}{l}\text { Social (politicas y acciones } \\
\text { de apoyo o indicidencias } \\
\text { sobre derechos de } \\
\text { asociación, trabajo forzado e } \\
\text { infantil, pueblos indígenas) }\end{array}$ & 17 & 17 & 19 & 17 & 17 & 18 & 19 & 20 & 19 \\
\hline $\begin{array}{l}\text { Carga ponderada indica- } \\
\text { dores de gestión social }\end{array}$ & 64 & 59 & 57 & 64 & 64 & 59 & 59 & 60 & 61 \\
\hline
\end{tabular}

Fuente: Elaboración propia basada en informes de sostenibilidad del Grupo México (2006-2014).

Como se observa en la tabla 8, la visión significativa de la sostenibilidad del Grupo México comprende el concepto ambiental, social y económico y elimina a los terceros interesados, centrándose en el gobierno corporativo (desde el $42 \%$ hasta el 52\%) y dando una ruta de atención en los informes.

En desarrollo sostenible y cadena de valor, el de mayor carga ponderada es el de desempeño económico con valores arriba del $40 \%$ (resaltado), en este concepto se enmarca el valor económico directo generado y distribuido, incluyendo ingresos, costos de explotación, retribución a empleados, donaciones y otras inversiones en la comunidad, beneficios no distribuidos y pagos a proveedores de capital y gobiernos. La atención a aspectos ambientales se encuentra en un valor cercano del $30 \%$, desde $34 \%$ al $25 \%$, sin indicar alteraciones significativas, refiriéndose a emisiones, vertidos, descargas y residuos, aspectos normados por ley.

El aspecto de mayor número de acciones es la gestión social, direccionado hacia el ambiente laboral. Este aspecto muestra contrastes de atención partiendo del $26 \%$ al $36 \%$ en las prácticas laborales, con una tendencia leve de crecimiento del 10\%; mientras que el enfoque de Derechos humanos disminuye y va desde el $21 \%$ hasta el $6 \%$, expresando una pérdida de interés $y$, finalmente, el aspecto social, en el que la mayor atención son los pueblos originarios y controversias de territorio que se mantiene entre un $17 \%$ y $19 \%$. La suma del enfoque de sostenibilidad se presenta en el gráfico 2 . 
Gráfico 2. Enfoque sostenible Grupo México 2006-2014

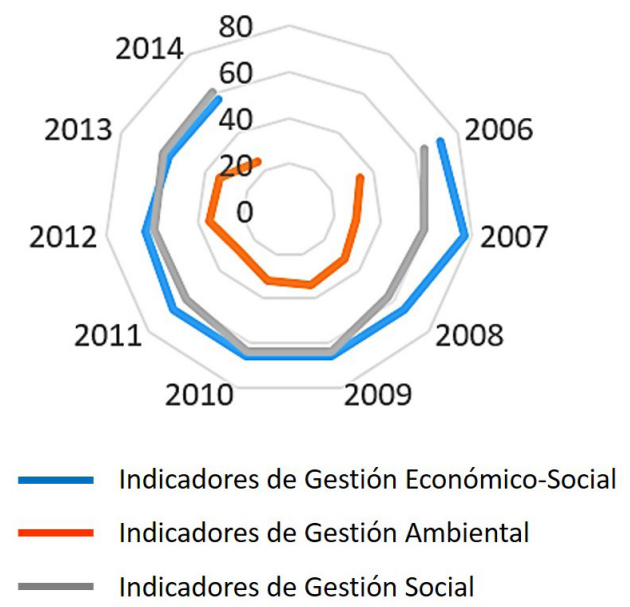

Fuente: Elaboración propia con base en informes de sostenibilidad del Grupo México.

El gráfico 2 permite comprender el contenido de los informes, tomando en cuenta que los valores concéntricos son el valor ponderado de las actividades atendidas en cada año del período estudiado (2006-2014). Los indicadores económico-sociales y sociales están en el mismo nivel; mientras que el ambiental tiene una atención de baja importancia.

\section{Conclusiones}

La industria minera en Méjico es importante en la actividad económica del país, siendo un atractivo para la inversión extranjera; es básicamente de explotación y afecta los recursos naturales limitados y a las comunidades aledañas. En la industria minera participan una empresa líder y otras que realizan distintas actividades como parte de su cadena de valor.

El desarrollo sustentable, como paradigma, requiere un compromiso de atención y racionalidad en el uso de los recursos naturales y su reflejo económico y social. El enfoque evolucionista de la sostenibilidad contradice la importancia de controlar el deterioro antropogénico de la industria minera, situación aprovechada por los grupos mineros en Méjico para interpretar su compromiso. La industria minera provoca afectaciones a la salud comunitaria y contamina de forma directa los ecosistemas, por la extracción de minerales y el proceso químico que realiza.

Los argumentos sostenibles de la industria minera son, entre otros, el beneficio social que otorga al crear empleos, infraestructura y apoyo 
comunitario. La contaminación de la industria minera es constante y acumulativa, utilizando eficazmente la imagen de buen ciudadano y buenas prácticas al atender una gestión social paralela a su actividad primaria, fuera de su cadena de valor.

La extracción y beneficio de minerales no se considera desde el enfoque de sostenibilidad en la industria minera, viéndose la extracción como un recurso, la fuente de ingresos y razón de operación en la empresa líder y en toda la cadena. Los indicadores ambientales no pueden ser relacionados con la actividad primaria ni con las de soporte. Un resultado inesperado es la baja atención de indicadores para informar a terceros interesados, lo cual puede explicarse por el alcance del beneficio económico del corporativo. No obstante, el Grupo México se distingue como líder en obras sociales y un manejo de imagen verde y compromiso. Su posición es negociadora con pueblos originarios por uso del territorio y el bienestar de su planta laboral y su familia, dejando invisible el daño ambiental y el efecto en la salud comunitaria.

\section{Referencias bibliográficas}

1. ALFIE-COHEN, Miriam. (2015). Conflictos socio-ambientales: la minería en Wirikuta y Cananea. El Cotidiano, Vol. 191. Pp. 97-108. Disponible en Internet: https://www. redalyc.org/pdf/325/32538023011.pdf Consultado: 17.07.2019.

2. AMPUERO, José Antonio. (2012). Cadena de valor. Disponible en Internet: http:// documents.mx/documents/cadena-de-valor-558494c24d676.html Consultado: 20.07.2019.

3. AZAMAR, Aleida y PONCE, José Ignacio. (2014). Extractivismo y desarrollo: los recursos minerales en Méjico. Problemas del desarrollo, Vol. 45, № 179. Pp. 137-158. Disponible en Internet: http://www.scielo.org.mx/pdf/prode/v45n179/v45n179a7. pdf Consultado: 20.07.2019.

4. CARMONA-GARCÍA, Uriel Fabián, CARDONA-TRUJILLO, Harold y RESTREPOTARQUINO, Inés. (2017). Gestión ambiental, sostenibilidad y competitividad minera. Contextualización de la situación y retos de un enfoque a través del análisis del ciclo de vida. Dyna, Vol. 84, № 201. Pp. 50-58. https://doi.org/10.15446/dyna.v84n201.60326

5. CORRAL, Víctor. (2010). Psicología de la sustentabilidad. Méjico: Editorial Trillas. 292 pp.

6. CORREA, María Emilia. (2004). Responsabilidad social empresarial: una nueva forma de hacer negocios. Revista Futuros, Vol. 2, № 6. Pp. 3-4.

7. DELGADO-RAMOS, Gian Carlo. (ed.) (2010). Ecología política de la minería en América Latina: aspectos socioeconómicos, legales y ambientales de la mega minería. Ciudad de Méjico: Universidad Nacional Autónoma de México. 520 pp. 
8. DÍAZ, Rafael y VALENCIANO, Jorge Andrey. (2012). Gobernanza en las cadenas globales de mercancías/valor: una revisión conceptual. Economía y Sociedad, Vol. 17, № 41. Pp.9-27. Disponible en Internet: https://www.revistas.una.ac.cr/index.php/economia/ article/view/4906/4718

9. FUENTE, Mario Enrique y BARKIN, David. (2013). La minería como factor de desarrollo en la sierra Juárez de Oajaca. Una valoración ética. Revista Problemas del Desarrollo, Vol. 44, № 172. Pp.123-144. Disponible en Internet: http://www.scielo.org.mx/scielo. php?script=sci_arttext\&pid=S0301-70362013000100007

10. GAYTAN, Edgar David y BENITA, Francisco Javier. (2014). La industria minera en Méjico: patrones de desempeño y determinantes de eficiencia. Lecturas de Economía, Vol. 1, № 80. Pp. 103-131. Disponible en Internet: http://www.redalyc.org/articulo. oa?id=155230074004

11. GRACIDA, Juan José. (2009). Ferrocarriles y minería en Sonora durante el porfiriato (1880-1910). Méjico: Universidad de Sonora. 200 pp.

12. GUAJARDO, Alberto. (2013). Los impactos de la sostenibilidad en la Cadena de Valor de la organización. CapacitaRSE. Disponible en Internet: http://www.cursosderse. com/2013/05/paper-sobre-sostenibilidad-en-la-cadena-de-valor-de-capacitarse/ Consultado: 24.07.2019.

13. GRUPO MÉXICO S.A.B (2006 al 2014). Informe sustentable anual. Disponible en Internet: http://www.gmexico.com/desarrollo-sustentable/reportes Consultado: 12.06.2019.

14. KAPLINSKY, Rafael \& MORRIS, Mike. (2001). A handbook for value chain analysis. Otawa: International Development Research Centre. 113 pp.

15. MÉJICO. Instituto Nacional de Estadística y Geografía. INEGI. (2014). La Minería en Méjico. Serie estadísticas sectoriales. Disponible en Internet: http://internet.contenidos.inegi. org.mx/contenidos/Productos/prod_serv/contenidos/espanol/bvinegi/productos/ integracion/sociodemografico/Mineria/2014/702825067069.pdf

16. MÉJICO. Minería en Sonora (s.f.). CD. Obregón en Sonora, Fierro por la 200. Disponible en Internet: https://obson.wordpress.com/tag/mineria/ Consultado: 23.07.2019.

17. MÉJICO. Municipios de Sonora (s.f.). Mapa municipios de Sonora. Disponible en Internet: https://tlaxcala.quadratin.com.mx/nacional/declara-segob-emergencia-para-11-municipios-de-sonora/ Consultado: 25.07.2019.

18. MÉJICO. Secretaría de Desarrollo Económico. SEDECO. (2015). Perfiles Industriales de San Luis Potosí.

19. MÉJICO. Secretaría de Economía. (2014a). Panorama Minero del Estado de Sonora.

20. MÉJICO. Secretaría de Economía. (2014b). Pro.Méjico. Disponible en Internet: http:// mim.promexico.gob.mx/Documentos/PDF/mim/FE SONORA vf.pdf Consultado: 20.06.2018.

21. MÉJICO. Secretaría de Economía y Servicio Geológico Mejicano. SE-SGM. (2014). Panorama Minero del Estado de San Luis Potosí. 
22. MÉJICO. Secretaría de Medio Ambiente y Recursos Naturales. (2001). Ley general del equilibrio ecológico y la protección al ambiente y disposiciones complementarias. Editorial Porrúa. Colección leyes y códigos de Méjico. Tomo II. Vigésima edición actualizada.

23. MINING ENVIRONMENTAL MANAGEMENT (2001a). Water management to reduce cyanide related risks. Ed. Mining Environmental Management. Vol. mayo 2001. № 27.

24. MINING ENVIRONMENTAL MANAGEMENT (2001b). Sound environmental practice in exploration drilling. Mining Environmental Management, Vol. julio 2001. Pp. 20-22.

25. PORTER, Michael Eugene. (1985). Competitive Advantage. Creating and sustaining superior performance. New York: The Free Press. 557 pp.

26. QUINTERO, Johana y SÁNCHEZ, José. (2006). La cadena de valor: Una herramienta del pensamiento estratégico. Telos, Vol. 8, №3. Pp. 377-389. Disponible en Internet: ttps:// www.redalyc.org/pdf/993/99318788001.pdf

27. SÁNCHEZ-SALAZAR, María Teresa. (2010). La estructura territorial de la minería mejicana al inicio del tercer milenio (pp. 97-132). En: DELGADO-RAMOS, Gian Carlo (ed.), Ecología política de la minería en América Latina: aspectos socioeconómicos, legales y ambientales de la mega minería. Ciudad de Méjico: Universidad Nacional Autónoma de México.

28. SAYAGO, Sebastián. (2014). El análisis del discurso como técnica de investigación cualitativa y cuantitativa en las ciencias sociales. Cinta de Moebio, № 49. Pp. 1-10. http://dx.doi.org/10.4067/S0717-554X2014000100001

29. SILVA, Letizia. (2010). Implicaciones sociales en la legislación ambiental: el proceso de evaluación de impacto ambiental de minera San Xavier (pp. 213-250). En: DELGADORAMOS, Gian Carlo (ed.), Ecología política de la minería en América Latina: aspectos socioeconómicos, legales y ambientales de la mega minería. Ciudad de Méjico: Universidad Nacional Autónoma de México.

30. VELÁSQUEZ, Raúl. (2009). Hacia una nueva definición del concepto "política pública". Desafíos, № 20. Pp. 149-187. Disponible en Internet: https://www.redalyc. org/pdf/3596/359633165006.pdf Consultado: 20.07.2019.

Para citar este artículo:

DE LA ROSA, María Eugenia, HERNÁNDEZ, Patricia, VEGA, Miguel Ángel. (2020). La industria minera y su enfoque de sostenibilidad en Méjico. Teuken Bidikay, Vol. 11, № 16. Medellín: Politécnico Colombiano. Pp. 175-200. doi: 10.33571/teuken.v11n16a8

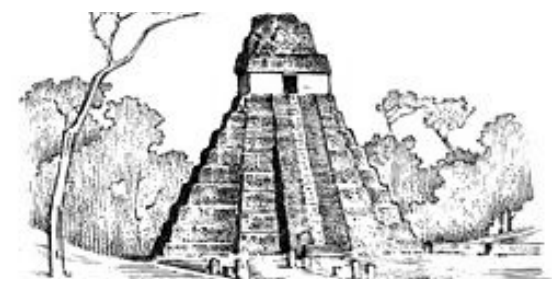

